\title{
The assessment of the visual perception in viewshed analysis for the landscape settings
}

\author{
Enrico Fabrizio, ${ }^{1}$ Gabriele Garnero ${ }^{2}$ \\ ${ }^{1}$ University of Torino, DISAFA (Dept. of Agricultural, Forest and Food Sciences), Torino, Italy; \\ ${ }^{2}$ University and Polytechnic of Torino, DIST (Dept. of Regional and Urban Studies and Planning), \\ Torino, Italy
}

\begin{abstract}
Visibility studies for rural and forest landscape are well established and conducted by means of standard GIS tools that compute the viewshed (a binary representation of the visibility of a location from a certain viewpoint) and cumulative viewsheds (integer representations of the visibility of a location from more viewpoints obtained with raster algebra). However, in order to go beyond the sole geometric information if a cell is visible or not, some authors have introduced various concepts that are based on the visual magnitude or visual exposure. These concepts also take into account the target magnitude, the atmospheric extinction, the colour difference to the background and the visual acuity. These calculations may be complex, extremely time consuming and not affordable with standard GIS tools, because they require specific programming tools. Besides, depending on the application, the factor that affects the visibility may be the distance, the atmospheric extinction, the contrast, etc. In this work, we concentrate on the problem of the calculation of the landscape sensitivity, which defines the degree to which a given landscape is potentially affected by possible changes by means of viewsheds analyses. An example in rural settings is presented in order to demonstrate the problems that arise in real applications and the possible solutions.
\end{abstract}

Correspondence: Gabriele Garnero, DIST, Università e Politecnico di Torino Via Leonardo da Vinci, 44, 10095 Grugliasco (T0), Italy.

Tel. +39.011.670.5518 - Fax + 39.011.670.5516.

E-mail: gabriele.garnero@unito.it

Key words: viewshed analysis; landscape; visual perception.

Contributions: the authors contributed equally.

Conflict of interest: the authors declare no potential conflict of interests.

Funding: no source of funding.

(C) Copyright E. Fabrizio and G. Garnero, 2013

Licensee PAGEPress, Italy

Journal of Agricultural Engineering 2013; XLIV(s2):e95

doi:10.4081/jae.2013.s2.e95

This article is distributed under the terms of the Creative Commons Attribution Noncommercial License (by-nc 3.0) which permits any noncommercial use, distribution, and reproduction in any medium, provided the original author(s) and source are credited.

\section{Introduction}

It is well known that a new development can modify the viewing conditions of a landscape. This is indicated as a visual impact, however it is seldom an easy task to determine the effect of the view obstructions and the re-shaping of the skyline, both in urban (Moser et al., 2010) and rural areas. It is necessary to take into account, besides the topography, the building elevations and the urban atmospheric visibility. New cartographic products can give new instruments to regional planners. The DTM and orthoimages databases can produce cartography useful in doing the regional planning such as the landscape sensitivity maps. The landscape sensitivity can be defined as the degree to which a given landscape could potentially be affected by possible changes, such as development (Bell, 2012). The metrics of a landscape sensitivity map should be able to identify:

how much territory can be seen from a certain viewpoint (quantitative concept indicating if the viewpoint can be seen from large areas or only from some specific points);

- how a portion of territory is seen (qualitative concept indicating from which distance it is seen and if this vision is impacting on the observer).

In order to perform maps of the landscape sensitivity it is necessary to use GIS procedures that consider together both terrain and built environment representations and model the interaction between humans and the space. However, visibility studies, especially those referring to rural and forest landscape analysis, are usually based on only terrain representations (triangulated irregular network - TIN or regular square grid of elevations - DEM) and must recur to some simplifications in order to take into account vegetation and other obstacles that affects the visibility (e.g. create a vegetation elevation model that is summed to the DEM).

Another characteristic of this work is to go beyond the standard binary approach that is used in visibility analysis (an integer result to identify if the cell of a raster is visible or not), taking into account more realistic factors that depend on the human vision and on the outdoor environment.

\section{Materials and methods}

Visibility studies were conducted in the past by means of isovists (Benedikt, 1979). An isovist may be defined as the visual field (set of points) that is wholly visible from a certain single point that is the feature of interest and that is called vantage point. If the isovist is computed on a plan, in a $2 \mathrm{D}$ representation the isovist is the set of points that are visible from the vantage point, disregarding the effect of the terrain morphology and the different heights of the surrounding buildings. In this case, an isovist is mapped as the continuous area of a two 
dimension polygon. With the creation of isovist generating computer applications (Dalton\& Dalton, 2001), there has been the possibility of moving the vantage point along a path generating a field of isovists and studying how the isovist properties vary along the path. However the drawback of an isovists is that in $2 \mathrm{D}$ an isovist does not take into account the possibility to look beyond an obstacle (Llobera, 2003).

A viewshed is a binary representation of the visibility of a location from a certain viewpoint and is usually computed by means of standard functions of GIS software tools from the DTM (Digital Terrain Model). The result is a Boolean variable that identifies if each cell is visible (value 1) or not (value 0 ) from a certain viewpoint. When the results of various viewsheds from different viewpoints are added up using raster algebra of GIS tool, the result is called cumulative viewshed and is characterized by an integer result: in this way how many viewpoints are seen at cell can be identified.

In order to go beyond the sole information if a cell is visible or not which is typical of the viewsheds, some authors have introduced the visual magnitude, which takes into account also the amount of a specific feature that is visible on the observer view. The first consideration on which this concept is based is that the visible size of an object diminishes as the view distance increases. The visual magnitude result is a floating point whose values are from 0 (no visibility) to 1 (complete visibility) and is computed taking into account the fact that the visible area decreases with the square of the distance. Different formulations for the calculation of the visual magnitude can be found on the literature (Grêt-Regamey et al., 2007; Chamberlain \& Meitner, 2013). As can be easily understood, in reality visual magnitude assumes very low values, because they have the physical meaning of the amount of area occupied on an observer view. Again, also in the case of the visual magnitude only geometrical aspects are considered, while other authors have introduced the concept of visual exposure (Domingo-Santos et al., 2011) in order to take into account also the atmospheric extinction, the colour difference to the background and the visual acuity.

Visual magnitude and visual exposure concepts have been widely used in the rural and forest landscape analysis (Kearney et al., 2008; Domingo-Santos et al., 2011; Jakab \& Petluš, 2012; Chamberlain \& Meitner, 2013).

Viewsheds and cumulative viewsheds can be easily calculated by means of standard GIS tools, however they suffer from the limitation due to the lack of the visual attenuation with distance, so that when the distance increases the results of a viwesheds analysis are merely theoretical.

The effect of the visual attenuation with distance is due, from a physical point of view, to:

the visual acuity of the human eye;

the atmospheric visibility;

the contrast between the target and the surrounding (e.g. the sky).

The visual acuity is defined as the inverse of the minimum apparent diameter $a$, measured in minutes of arc. The $\operatorname{arc} a$ can be obtained from the distance of observation $d$ and the object size $D$ as

$$
a=\frac{180 \cdot 60}{\pi} \arctan \left(\frac{D}{d}\right)
$$

The visual acuity depends on the age of the subject, on the illuminance level and on the contrast, and ranges from 2 (that is $0.5^{\prime}$ ) for young people with the greatest contrast, to 0,2 (that is $5^{\prime}$ ) for elderly people with the lowest contrast (Fortuin, 1951). Usually a value of about 1, that is an angle of 1' (minute), is considered to be a threshold value of visibility in many applications. The limit visibility distance due to visual acuity will be indicate hereinafter as $d_{1, v}$ and is equal, from Eq. 1, to

$$
d_{l, v}=\frac{D}{\tan \left(a \frac{\pi}{60 \cdot 180}\right)} \cong D \frac{60 \cdot 180}{a \pi}
$$

Considering an object that has a size of $20 \mathrm{~m}$, the maximum distance at which it can be seen is $69 \mathrm{~km}$ with a visual acuity of 1 .

Even though visual acuity sets a physical limit to the mutual view distance between two points in a GIS model, only in some particular weather conditions (e.g. clear winter days) the visual acuity limitation may be the predominant one. In fact, in practice in many cases the atmospheric visibility may limit the maximum visibility distance rather than the visual acuity, however, this aspect is of little interest in the field of landscape sensitivity studies because the landscape perception is supposed to be evaluated during good weather conditions.

The third aspect that affects the visibility of an object in the landscape is the colour contrast between the target and the immediate surroundings. In many procedures for the visual impact assessment (e.g. Torres-Sibille, 2009; Chiabrando et al., 2011) this aspect is taken into account computing the colour difference - sometimes erroneously called contrast - expressed as the Euclidean distance between the two points in the CIELAB colour space. In visibility studies other authors calculates the contrast as the difference between the average lightness of the object and the background object (e.g. Shang \& Bishop, 2000), thus considering only a difference in lightness on a gray scale.

\section{Implementation on a case study}

The visibility analysis was conducted on the case study of a path of 14 stages (called "stations") that connects the house of Don Bosco to that of S. Domenico Savio in the province of Asti. The 14 "stations" are dedicated to 14 young people in the history of salvation in the Scriptures. This path is intended to be traveled on foot and is $1200 \mathrm{~m}$ long. A representation of this path is reported in Figure 1. This path is currently under construction and is called "Strada del Papa" (Path of the Pope) since it is the normal road for access to the Salesians sites, built in 1988 on the occasion of visit of Pope John Paul II for the centenary of the death of Don Bosco. A firt part of this route, from the house of Don Bosco (the saint of youth) to Saint Dominic Savio (the first young Santo), will be equipped. It is an itinerary in the green of the hill

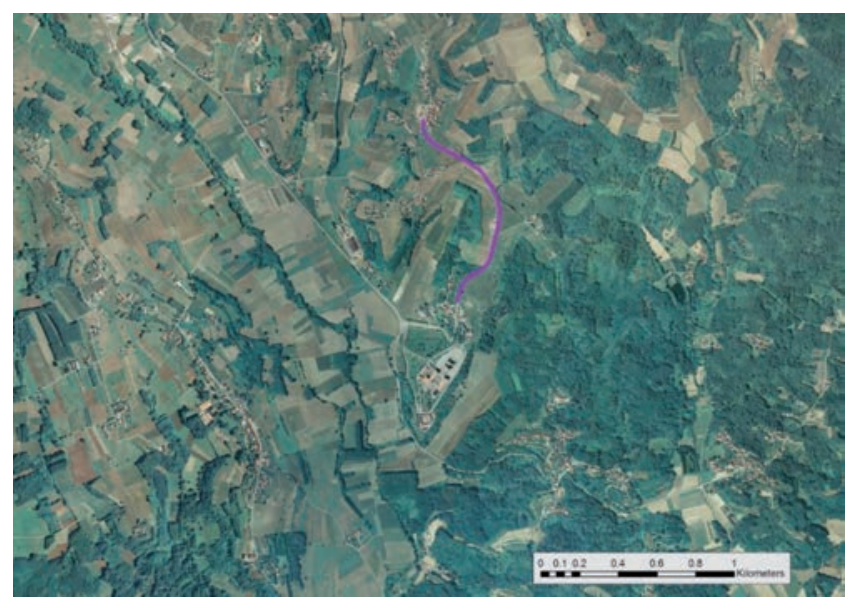

Figure 1. The path from the house of Don Bosco to the house of $S$. Domenico Savio. 
of Asti already used by groups, families and individuals to take walks or meditate in a favorable, full of silence, beautiful and peaceful natural environment (Figure 2).

Along this path the "Way of biblical youth" will be built. It is a journey dotted with 14 modern kiosks, as many are the Stations of the Cross, but focusing on young people of the Old Testament (The Sacrifice of Isaac; Joseph, savior of its people; the calling of Samuel, David, the boy anointed king by Samuel; Esther, the girl who saves his people; the vocation of the prophet Jeremiah; Hananiah, Mishael and Azariah, the three youth loyal to God against the idolatrous king of Babylon) and the New Testament (Mary of Nazareth, the girl of the Magnificat; the Holy Innocents; twelve year old Jesus among the Doctors in the Temple of Jerusalem; the resurrection of the son of the widow of Nain; the vocation of Andrew and John; the boy the multiplication of the loaves and fishes; the blessing of children).

The kiosks, made of metal and designed by Aldo Gervasio, will host the paintings by the two Polish Salesians painters, the brothers Robert and Leszek Kruczek.

\section{Digital terrain model - DTM}

The new DTM of Piedmont Region has a cell size of $5 \mathrm{~m} \times 5 \mathrm{~m}$. Data for the present work have been provided by Regione Piemonte survey aimed to the production of a digital orthoimage at 1:5000 scale and a digital terrain model at Level 4 in accordance with Intesa specifications (CISIS, 2011) as reported in Table 1 (Godone and Garnero, 2013).

A LIDAR survey was carried out by the employment of ALS 50 II sensor (Leica Geosystems) with MPIA (Multiple Pulse In Air) technology, with the following features:

- Maximum Pulse Rate: $150.000 \mathrm{~Hz}$ (150.000 points/second);

- Maximum scanning frequency: $90 \mathrm{~Hz}$ (90 lines/second);

- $\quad 4$ echoes $\left(1^{\circ}, 2^{\circ}, 3^{\circ}\right.$ and last);

Flying height: 200 - $6000 \mathrm{~m}$ above ground;

- Field Of View (FOV): $10^{\circ}-75^{\circ}$;

- Side overlap: 200 - $600 \mathrm{~m}$;

- Intensity measured each echo.

The LiDAR survey of the complete territory of Regione Piemonte was characterized by the following parameters:

FOV (Field Of View): $58^{\circ}$;

LPR (Laser Pulse Rate): 66.400 Hz;

Scan Rate: $21.4 \mathrm{~Hz}$;

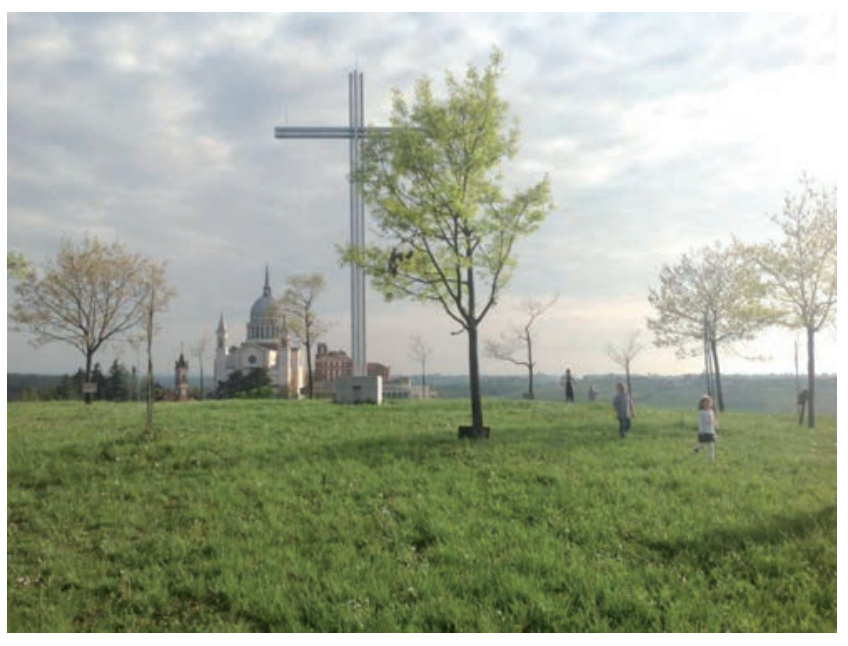

Figure 2. A view from the "Path of Pope".
Average Point Density:0.22 pts/m²

Average Point Spacing: $2.12 \mathrm{~m}$;

The study area refers to the $156160,157130,174040$ and 175010 Sections of the regional DTM (Digital Terrain Model), which has a cell size of $5 \times 5 \mathrm{~m}$. The representation of this DTM is reported in Figure 3 where it can be noted that the "Path of Pope" is on a hill and that can be seen from both the valleys on east and west.

\section{Base cartography}

The base map produced by the Unione Collinare Alto Astigiano in 2009 was used for this work. Specifically, it is part of a series of productions partially financed by the Fondazione CRT (Cassa di Risparmio di Torino) executed on the basis of common specifications promoted by the Piedmont Region in the implementation of the national rules that go under the IntesaGIS programme. The standardization includes specific standardized contents both in the various productions and at different scales, so that it is possible for the higher-level Public Administration, to retrieve information in order to update their territorial databases.

Table 1. Specifications of the DTM level 4 - CISIS document "Ortoimmagini e modelli altimetrici a grande scala - Linee Guida (Large scale orthoimagery and elevation models - Guidelines)" shows Level values (meters)

\begin{tabular}{lc} 
Type & DEM or DSM \\
Accuracy: bare ground PH(a) & 0.30 \\
Height accuracy: with tree cover > 70\% PH(b) (DEM) & 0.60 \\
\hline Height accuracy: buildings (DSM) PH(c) & 0.40 \\
Height tolerance: bare ground TH(a) & 0.60 \\
\hline Height tolerance: with tree cover > 70\% TH(b) (DEM) & 1.20 \\
Height tolerance: buildings (DSM) TH(c) & 0.80 \\
\hline Planimetric accuracy: PEN & 0.30 \\
Planimetric tolerance: TEN & 0.60 \\
\hline Cellsize: & 5 \\
\hline
\end{tabular}

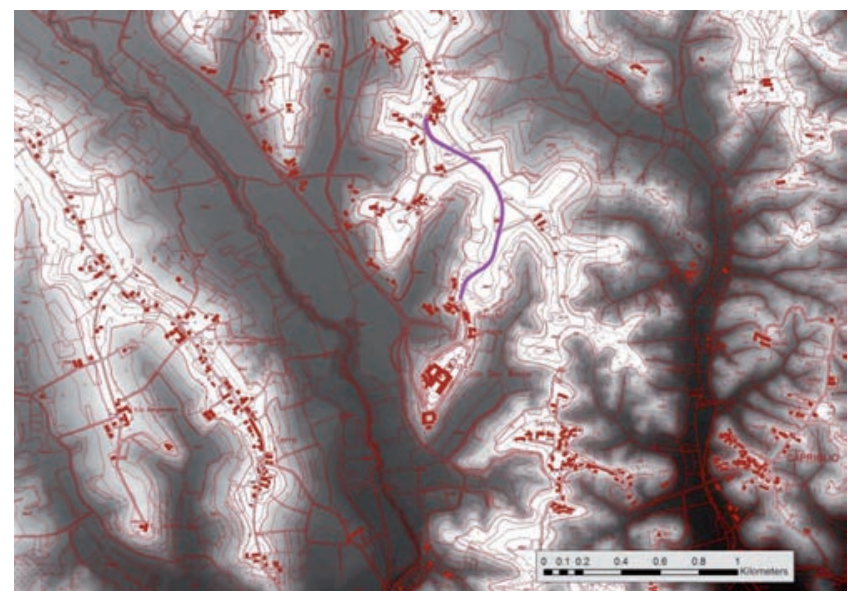

Figure 3. DTM of case study area with the indication of the "Path of Pope" under consideration. 


\section{GIS processing}

The ArcGIS 10.1 tool was used in all the processing. It is believed that, in a journey on foot, portions of land that are at different distances from the viewers should be classified with a different landscape sensitivity: it is evident from everyday experience that near objects can cause a perception of greater evidence than distant objects, even though those last are, from the point of view of the visibility, are within the visible space and have a size above the threshold level of visual acuity (see Eq. 2).

For the implementation of this work the following classification as a function of visual depth was adopted, in accordance with the indications found in the literature (de la Fuente de Val et al., 2006; Brabyn and Mark, 2011). The levels of visual depth identified were the followings:

- foreground, with 0-500 m visual depth. In the foreground individual components of the scene are distinguishable and multi-sensory factors intervene (sounds, smells);

- $\quad$ intermediate ground 1 , with 500-1000 m visual depth. In the inter-

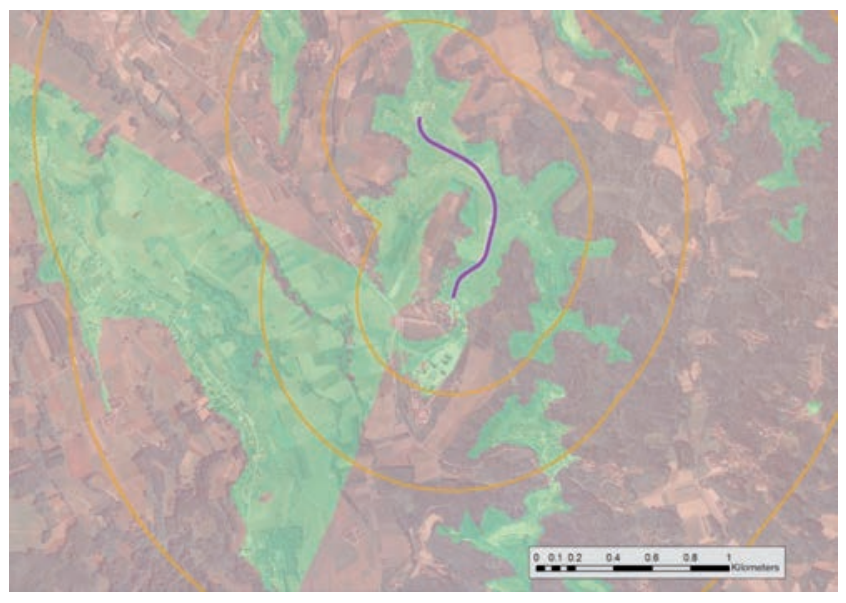

Figure 4. Visibility map of the "Path of Pope" under consideration with the three levels of visual depth (green: visible, red: invisible).

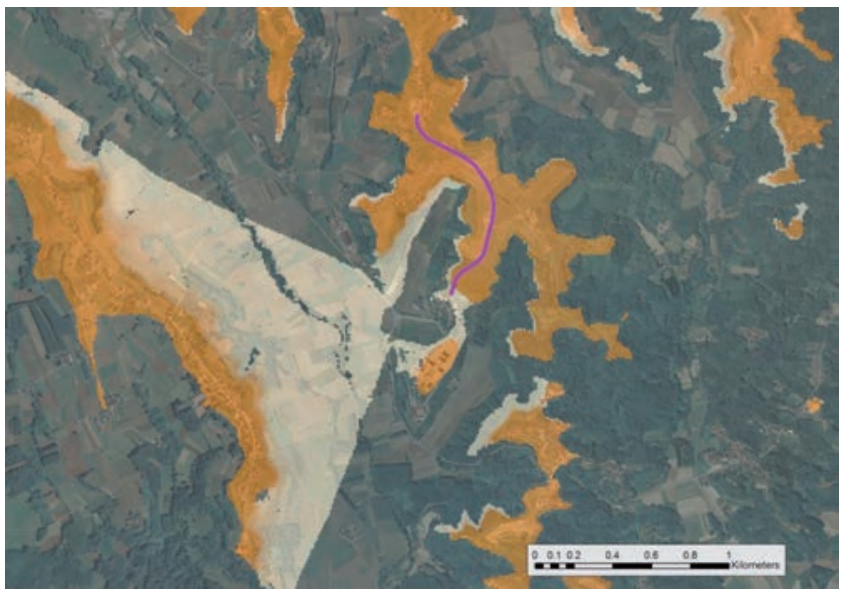

Figure 5. Landscape sensitivity of the "Path of Pope" under consideration. mediate ground individual elements are noticeable compared to the background;

intermediate ground 2, 1.000-2.000 m visual depth;

- background, $2.000 \mathrm{~m}$ visual depth. The background is of interest only in case of relevant size of the objects or distinguished elements.

The previous values of distance are suitable for the specific contest; different distances may be defined for other topographic and landscape contexts (e.g. the visibility of a prominent mountain into an alpine landscape or the visibility of a skyscraper into a urban landscape).

The horizontal aperture angle was set to $360^{\circ}$ (full horizontal visibility).

The analyses were then performed by adopting the Multiple Ring Buffer analysis tool available in the ArcGIS Geoprocessing tools.

No limit visibility distance for the atmospheric extinction was assumed since the landscape sensitivity should be studied in the best visibility conditions.

\section{Results}

In the following Figures 4 and 5 the visibility maps are reported. The first map is the visibility of the "Path of the Pope" computed with a discretization of the path with the indication of the various visual depths for foreground (inner curve), intermediate grounds and background. A green land unit means that this land unit sees or can be seen from at least one point of the "Path of the Pope". As can be seen from the figure, large extent of the study area can be seen from the path, especially in the foreground level.

In order to give a quantitative evaluation of the landscape sensitivity, using raster algebra, in Figure 5 each visible land unit is classified as a function of the occurrence of the visibility for the various points in which the "Path of the Pope" was discretized. It can be seen that the for most of the green area of Figure 4, the landscape sensitivity is maximal, because the land unit can see or can be seen from all points in the path. This mapping was obtained by discretizing the path in all the characteristic points, inserting also other 100 points: overall, a total of 443 points were considered and each land unit is classified depending on the incidence of the number of points that see / are seen from the territory.

\section{Conclusions}

The modern cartographic supports that are already entered in the normal production process, may be used, in addition to the technical applications for which they are ordinarily prepared, also as interesting databases that allow rethinking the traditional cartography currently used by city and landscape planners.

The examples presented in this paper can in fact provide those involved in the design of planning instruments and operators that check the landscape compatibility of new developments with objective instruments for assessing the actual degree of visual impact of the works under project and, equally objectively, the various proposals (transformation or not, mitigations, green screens, etc....). It is in fact possible to predict the points of visibility and the landscape sensitivity in order to guide and generate an urban development that does not interfere with the landscape settings. In the particular study case, the locations that should be prevented from a large urban development can for example be seen on Figure 4.

Visibility analyses can also be a valuable means for the tourist development of a territory, also by means of new technologies (Garnero et al., 2013; Minucciani et al., 2013). 


\section{References}

Bell S. 2012. Sustainable Landscape. In: R.A. Meyers (ed.) Encyclopedia of Sustainability Science and Technology. Springer Science, New York, pp 10360-90.

Bendikt M.L. 1979. To take hold of space: isovists and isovist fields. Environment and Planning B. 6:47-65.

Brabyn L., Mark D.M. 2011. Using viewsheds, GIS, and a landscape classification to tag landscape photographs. Applied Geography. 31:1115-1122.

Chamberlain B.C., Meitner M.J. 2013. A route-based visibility analysis for landscape management. Landscape Urban Plann. 111:13-24.

Chiabrando R., Fabrizio E., Garnero G. 2011. On the applicability of the visual impact assessment $\mathrm{OAI}_{\mathrm{SPP}}$ tool to photovoltaic plants, Renew Sust Energy Rev. 15:845-850.

Dalton R.C., Dalton N. 2001. OmniVista. An Application for Isovist Field and Path Analysis. In Proceedings . 3rd International Space Syntax Symposium Atlanta 2001, pp. 25.1-25.10.

de la Fuente de Val G., Atauri J.A., de Lucio J.V. 2006. Relationship between landscape visual attributes and spatial pattern indices: A test study in Mediterranean-climate landscapes .Landscape Urban Plann. 77:393-407.

Domingo-Santos J.M., de Villaran R.F., Rapp-Arraras I., de Provence E.C.P. 2011. The visual exposure in forest and rural landscapes: An algorithm and a GIS tool. Landscape Urban Plann. 101:52-58.

Fortuin G.J. 1951. Visual power and visibility. PhD Dissertation, University of Groningen (NL).

Garnero G., Corrias A., Manigas L., Zedda S.V. 2013. VGI, Augmented Reality and Smart Web Application: Projects of Development in the Territory of the Sardinia Region, in B. Murgante et al. (Eds.):
ICCSA 2013, Part IV, LNCS 7974, pp. 77-92. Springer, Heidelberg. Godone, D., Garnero G. 2013. The role of morphometric parameters in Digital Terrain Models interpolation accuracy: a case study. European Journal of Remote Sensing, 46(1), 198-214.

Grêt-Regamey A., Bishop I.D., Bebi P. 2007. Predicting the scenic beauty value of mapped landscape changes in a mountainous region through the use of GIS. Environment and Planning B. 34:50-67.

Jakab I., Petluš P. 2012. Development of a program tool for the determination of the landscape visual exposure potential. Developments in Environmental Modelling. 25:375-390.

Kearney A.R. Bradley G.A., Petrich C.H., Kaplan R., Kaplan S., SimpsonColebank D. 2008. Public perception as support for scenic quality regulation in a nationally treasured landscape. Landscape and urban planning. 87:117-128.

Llobera, M. 2003. Extending GIS-based visibility analyses: the concept of visualscapes. Int. J. Geogr. Inf. Sci., 17 (1), 25-48.

Minucciani V., Garnero G. 2013. Available and Implementable Technologies for Virtual Tourism: A Prototypal Station Project, in B. Murgante et al. (Eds.): ICCSA 2013, Part IV, LNCS 7974, pp. 193204. Springer, Heidelberg.

Moser J., Albrecht F., Kosar B. 2010. Beyond visualisation - 3D GIS analyses for virtual city models. International Archives of the Photogrammetry, Remote Sensing and Spatial Information Sciences. vol. XXXVIII-4/W15:143-146.

Shang H., Bishop I.D. 2000. Visual thresholds for detection, recognition and visual impact in landscape settings. Journal of environmental psychology. 20:125-140.

Torres Sibille A., Cloquell-Ballester V., Cloquell-Ballester V., Ramirez M. 2009. Aesthetic impact assessment of solar power plants: an objective and subjective approach. Renew Sustain Energy Rev. 13:986999 . 